\title{
FACTORS INFLUENCING REFERRALS TO THE OUT-PATIENTS DEPARTMENT OF A LONDON TEACHING HOSPITAL
}

\author{
BY \\ ROY M. ACHESON*, ROGER BLANEY, W. J. H. BUTTERFIELD, \\ JOCELYN CHAMBERLAIN, AND MARY SCOTT-BROWN
}

From the Social and Preventive Medicine Unit, Department of Experimental Medicine, Guy's Hospital Medical School, London, S.E.1

Among the important steps taken with the introduction of the National Health Act in 1949 was ratification of an idea, which had been developing for some years, that the hospital out-patients' department should become a centre to which a general practitioner could refer any patient for a specialisi opinion. The Government, through the agency of the Ministry of Health and the Registrar General, has subsequently undertaken and published inquiries on hospital in-patient services (Ministry of Health and General Register Office, 1960, 1961) and others have commented on general practice (Logan and Cushion, 1958; Logan, 1960).

This has made possible an evaluation of these aspects of the National Health Service, but no data are yet available on the work done in out-patients' departments. Therefore, Guy's Hospital welcomed the opportunity of undertaking, with the support of the King Edward VII Hospital Fund, studies of outpatient services in London, to be conducted in close collaboration with other surveys of out-patient services elsewhere which are being carried out on a national scale under the auspices of the Nuffield Provincial Hospitals' Trust. In this paper some results of a pilot study of 271 patients attending certain out-patients clinics at Guy's as new patients are presented, and particular attention is paid to some of the factors which determined why they came to Guy's in preference to other hospitals.

\section{MeTHOD}

New out-patients only were studied. The term "new patient" is applied by the Guy's out-patients clerical staff to any person who attends with a letter of introduction. There are two categories:

(1) Patients attending any clinic for the first time. These may have been referred from elsewhere

\footnotetext{
*Present address: Dept. of Epidemiology and Public Health, Yale University School of Medicine, New Haven, Conn., U.S.A.
}

in the hospital, or more commonly from a practitioner outside the hospital.

(2) Patients who had attended a clinic in the past from which they were discharged, but who present themselves again with a new letter after an interval of at least one year.

The 271 patients studied were selected at random early each morning from those scheduled to attend a clinic, but this pilot investigation confined itself to those specialties which were housed in the main out-patients' building. * Information was obtained in part from the patient himself by asking standardized questions, and in part from his out-patients record sheet.

\section{FINDINGS}

Table I shows the reasons given by the patients for attending the out-patients department at Guy's rather than at another hospital. It shows quite clearly that the biggest single determining factor is the patient himself; for each patient who had the choice made for him by his doctor (56), there were two who made the choice themselves (119). These two clearly defined categories accounted for 65 per cent. of the 271 patients in our sample. The remaining 35 per cent. were divided equally between those

TABLE I

REASON FOR ATTENDING A CLINIC AT GUY'S HOSPITAL RATHER THAN ELSEWHERE

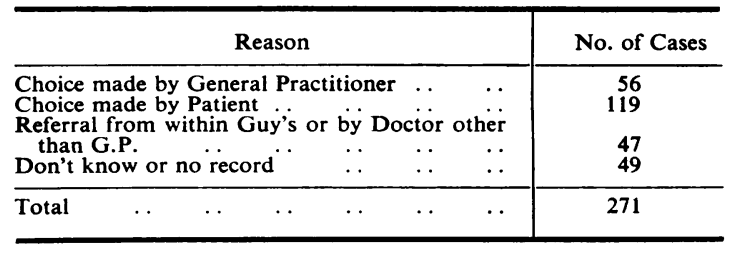

* Medicine, Surgery, Otorhinolaryngology, Dermatology, Paediattrics, Ophthalmology, Endocrinology, Neurology, Cardiology, Diabetes, Chest, Neurosurgery, Gynaecology, Thoracic Surgery, 81 
who had reached the clinic, where they were interviewed as "new" patients, from elsewhere in the hospital (47) and those who were unable to say clearly why they attended Guy's rather than another hospital (49).

A further analysis of the motivation underlying the choice of the 119 who themselves selected the hospital is shown in Table II: 69 (58 per cent.) came because of the goodwill the hospital had built up either with the patients themselves or with their acquaintances, and for 32 ( 27 per cent.) the selection was explained by geographical circumstances.

TABLE II

REASON FOR THEIR CHOICE GIVEN BY 119 PATIENTS WHO THEMSELVES SELECTED GUY'S

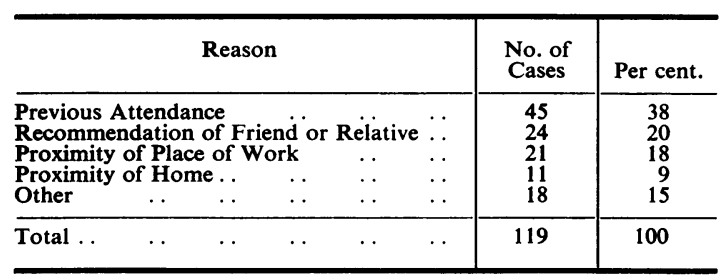

It is worth noting that in the latter group there were two who worked close to the hospital for each one who lived in the vicinity. However, as Table III shows, only 28 per cent. of all the patients lived really near to the hospital.

A breakdown which gives more detailed information about the effects of proximity and accessibility on the choice of hospital is given in Fig. 1. The
TABLE III

DISTANCE OF HOME FROM GUY'S HOSPITAL

\begin{tabular}{|c|c|c|}
\hline Distance (miles) & No. of Cases & Per cent. \\
\hline $\begin{array}{c}0- \\
1- \\
2- \\
5- \\
10-\end{array}$ & $\left.\begin{array}{l}47 \\
31 \\
45 \\
72 \\
76\end{array}\right\} 117$ & $\begin{array}{l}17 \\
11 \\
17 \\
26 \\
28\end{array}$ \\
\hline Total & 271 & 100 \\
\hline
\end{tabular}

doctor's influence in choosing Guy's increases steadily with the distance of the patient's home from the hospital, with a consequent decrease in the number of distant patients who make the choice either through their own judgment or at the suggestion of a friend or relative. Of the 56 referrals made to Guy's on the decision of the general practitioner, 24 (43 per cent.) were made by doctors who had themselves been trained at Guy's. Moreover, only 5 per cent. of the doctors living within 2 miles of the hospital were Guy's trained.

Patients' Occupations.-Table IV (opposite) shows the relationship between the occupation of the patient (or in the case of married women, of the husband) in relationship to the distance of the patient's home from the hospital. In this analysis the occupation has been classified in accordance with the social classes of the Registrar General (General Register Office, 1960), and it can be seen that the farther the patients live from the hospital the higher their social class; this relationship is most unlikely to be a chance finding $(P<0.001)$.

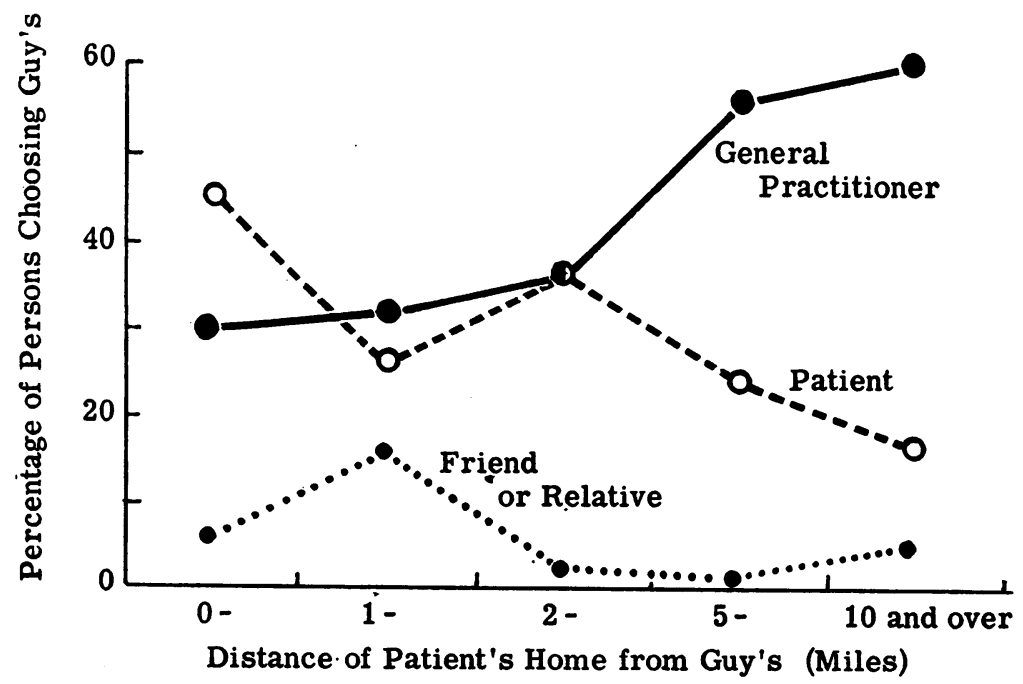

Fig. 1.-Choice of Guy's hospital related to location of patient's home, and extent to which the patient, the general practitioner, or a relative or friend were responsible for the selection 
TABLE IV

SOCIAL CLASS OF NEW OUT-PATIENTS, BY DISTANCE OF HOME FROM GUY'S HOSPITAL

\begin{tabular}{|c|c|c|c|c|c|c|c|}
\hline \multirow{3}{*}{$\begin{array}{l}\text { Social } \\
\text { Class }\end{array}$} & \multicolumn{7}{|c|}{ Distance of Home from Guy's Hospital (miles) } \\
\hline & \multicolumn{2}{|c|}{ Less than 2} & \multicolumn{2}{|c|}{$2-9$} & \multicolumn{2}{|c|}{10 and Over } & \multirow{2}{*}{ Total } \\
\hline & $\begin{array}{l}\text { No. } \\
\text { Ob- } \\
\text { served }\end{array}$ & $\begin{array}{c}\text { No. } \\
\text { Ex- } \\
\text { pected }\end{array}$ & $\begin{array}{l}\text { No. } \\
\text { Ob- } \\
\text { served }\end{array}$ & $\begin{array}{l}\text { No. } \\
\text { Ex- } \\
\text { pected }\end{array}$ & $\begin{array}{l}\text { No. } \\
\text { Ob- } \\
\text { served }\end{array}$ & $\begin{array}{c}\text { No. } \\
\text { Ex- } \\
\text { pected }\end{array}$ & \\
\hline $\begin{array}{l}I \text { and II } \\
\text { III } \\
\text { IV and V }\end{array}$ & $\begin{array}{r}6 \\
45 \\
24\end{array}$ & $\begin{array}{l}18 \\
42 \\
15\end{array}$ & $\begin{array}{l}31 \\
63 \\
19\end{array}$ & $\begin{array}{l}27 \\
63 \\
23\end{array}$ & $\begin{array}{l}26 \\
36 \\
10\end{array}$ & $\begin{array}{l}17 \\
40 \\
15\end{array}$ & \\
\hline Total .. & 75 & 75 & 113 & 113 & 72 & 72 & 260 \\
\hline
\end{tabular}

There was no record of the occupation of eleven of the patients.

The Introductory Letter.-Table $\mathrm{V}$ shows that more than three-quarters of the letters introducing patients to the hospital consultant were written by general practitioners. Most of the remainder were either cross-referrals from other out-patients' clinics or from the casualty department.

\section{TABLE V}

AUTHOR OF LETTER OF INTRODUCTION TO GUY'S HOSPITAL

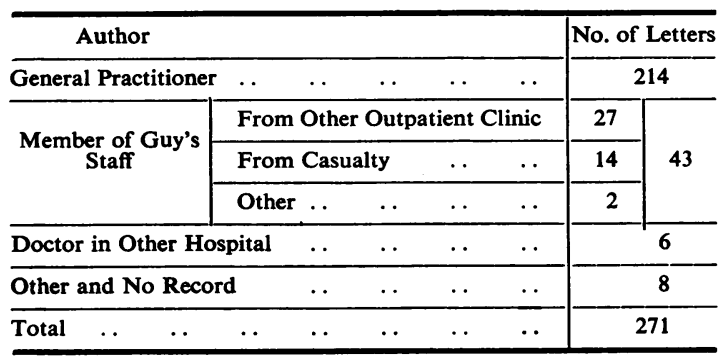

We found by scrutiny of 199 letters from general practitioners that a letter containing fifteen words or less in its main text could carry little clinical information, and could, therefore, be fairly described as "short". Fig. 2 shows a striking relationship between the proportion of short letters and the distance of the patient's home from the hospital. There is also a significant $(P<0.05)$ association between the number of words in the introductory letter and the social class of the patient (Table VI).

\section{TABLE VI}

SOCIAL CLASS BY LENGTH OF LETTER OF INTRODUCTION

\begin{tabular}{|c|c|c|c|c|}
\hline \multirow{2}{*}{ Social Class } & \multicolumn{3}{|c|}{ No. of Words in Letter } & \multirow{2}{*}{$\begin{array}{c}\text { Total } \\
\text { in } \\
\text { Class }\end{array}$} \\
\hline & $0-15$ & $16-100$ & 101 or More & \\
\hline $\begin{array}{l}\text { I and II } \\
\text { III } \\
\text { IV and V }\end{array}$ & $\begin{array}{r}3 \\
15 \\
10\end{array}$ & $\begin{array}{l}47 \\
76 \\
29\end{array}$ & $\begin{array}{r}5 \\
13 \\
1\end{array}$ & $\begin{array}{r}55 \\
104 \\
40\end{array}$ \\
\hline Total & 28 & 152 & 19 & 199 \\
\hline
\end{tabular}

$\chi^{2}(0)=11.39 ; 0.05>P>0.01$

This finding, though not surprising, is noteworthy in view of the results shown above in Table IV.

\section{Discussion}

Perhaps the most interesting aspect of the data presented above is the extent to which a hospital depends for its referrals upon goodwill. For those who live nearby this goodwill has been built up with the patients themselves, through their own experience or that of their relations and friends. That this tendency of patients to select teaching hospitals

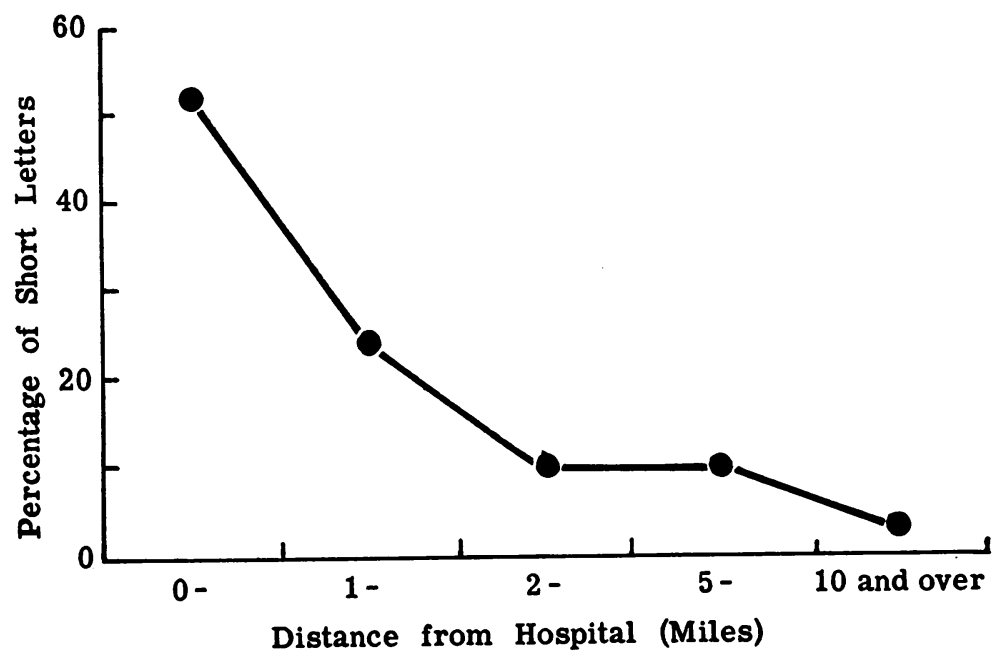

Fig. 2.-Diagram to show how the introductory letters of less than 15 words become fewer the greater the distance of the patient's home from the hospital 
is not confined to Guy's alone has been shown in a recent survey of practitioners' referral habits by Acheson, Barker, and Butterfield (1962), who found in two metropolitan areas of London that for the 57 per cent. of doctors who let the patient choose an out-patients' department, the choice tended to be a teaching hospital. When the doctor himself made the choice, however, his preference tended to be with a hospital run by the Regional Hospital Board. These findings are supported in the present study, for it was only among patients living more than 5 miles from the hospital that the influence of the doctor became a major factor in selecting Guy's, and here for many the goodwill evidently originated in student days, 55 per cent. of these doctors being Guy's trained. There were some other patients, however, with unusual complaints who were sent to consult doctors in Guy's with a national reputation as specialists.

The trend in social class is to some extent explained by the fact that according to the last published census (General Register Office, 1953) the proportion of persons of Social Classes IV and V living in Bermondsey and Southwark is 15 per cent. higher than in the County of London as a whole. However, this does not explain why, for a disproportionate number of Social Classes I and II, the doctors selected Guy's out-patients' department in preference to hospitals nearer at hand. Many factors presumably underly this pattern, including the ability to afford the travelling expenses to the hospital, the fact that many persons of Social Classes I and II work in city offices near the hospital, and the doctors' wishes to maintain contact with their old chiefs.

The analyses showing clearly-defined differences in the amount of information brought to Guy's in the patients' letters of introduction pose more questions than they answer. Are the majority of the letters from nearby short because the patients' illnesses are less complex than those referred from afar, or because the doctors are within easy telephoning distance, or because the patients are poorer people, or because the usual referral letter to any hospital is short, and those brought from afar are concerned with complex clinical problems and are therefore atypical? Or do those in Social Classes I and II prefer the anonymity of a large hospital some distance from home, and in supporting such an attendance does their doctor feel it is necessary to write a longer letter?

We propose to carry out a large study of a further 1,200 out-patients, randomly selected. This will permit a more detailed analysis and will perhaps answer some of these questions.

\section{SUMmary}

271 new out-patients attending Guy's Hospital were selected at random, and the following facts were observed:

(1) In the 175 cases in which the reason for choosing Guy's in preference to other hospitals was clearly determined, 119 patients had made the choice themselves. Previous satisfaction with Guy's, the advice of a relative or friend, and proximity of residence or work place were among the reasons given.

(2) Patients living at some distance from the hospital differed from those living within 2 miles of it in the following respects:

(a) They left the choice to their general practitioner more often.

(b) More of them were from the professional classes.

(c) They brought with them longer letters of introduction.

This research is supported by King Edward VII Hospital Fund.

\section{REFERENCES}

Acheson, R. M., Barker, D. J. P., and Butterfield, W. J. H. (1962). Brit. Med. J., 2, 1315.

General Register Office (1953)." "Census 1951. England and Wales. County Report: London".

(1960). "Classification of Occupations, 1960." H.M.S.O., London.

Logan, W. P. D. (1960). "Morbidity Statistics from General Practice," vol. 2 "Occupation", General Register Office Studies on Medical and Population Subjects No. 14. H.M.S.O., London.

and Cushion, A. A. (1958). Ibid., vol. 1 "General".

Ministry of Health and General Register Office (1960).

"Report on Hospital In-Patient Inquiry for 1958",

part I. H.M.S.O., London. (1961). Ibid, part II. 